\title{
Mechanical characteristics and flexural behaviour of fibre-reinforced cementitious composite containing PVA and basalt fibres
}

\author{
ZHI PIN LOH, KIM HUNG MO*® , CHEE GHUAN TAN and SHIH HORNG YEO \\ Department of Civil Engineering, Faculty of Engineering, University of Malaya, 50603 Kuala Lumpur, Malaysia \\ e-mail:khmo@um.edu.my
}

MS received 11 April 2018; revised 3 December 2018; accepted 4 January 2019; published online 27 March 2019

\begin{abstract}
Fibre-reinforced cementitious composite (FRCC) is a type of composite that uses high volume of fibres to attain ductile properties. In this research, the effects of two different fibres, namely polyvinyl alcohol (PVA) and basalt, on the mechanical properties of FRCC such as compressive, splitting tensile and flexural strengths were investigated. The fibres were used in varying volume fraction, which includes $1.0 \%, 1.5 \%$ and $2.0 \%$ and a hybrid combination of $1.5 \%$ basalt fibre with $1.5 \%$ PVA fibre for the preparation of the FRCC. The results showed that while the fibres had minimal effect on the compressive strength of FRCC, significant improvements in the splitting tensile and flexural strengths were found. In the comparison of the flexural performances, the introduction of PVA fibre in FRCC led to superior properties and it exhibited more ductile failure mode compared with basalt fibre and the optimum fibre dosage to be added was determined to be $1.5 \%$.
\end{abstract}

Keywords. Fibre-reinforced cementitious composite; PVA fibre; basalt fibre; mechanical properties; flexural behaviour.

\section{Introduction}

Fibre-reinforced cementitious composite (FRCC) is a type of high-performance concrete produced by adding fibres such as glass, polypropylene, polyvinyl alcohol (PVA), etc. to the cementitious matrix. As opposed to conventional concrete, which is brittle and has localized crack failure, FRCC has superior mechanical properties (tensile strength and flexural strength) and ductility, which is aided by the ability to exhibit multiple cracking. The function of fibres in the matrix is primarily in the post-cracking zone, which induces the fibre-crack interactions, including crack suppression, crack stabilization, crack bridging and fibre-matrix debonding [1].

When cracking initiates in the composite, stress is built up at the crack tip and because of the fibre-matrix interfacial bond, the fibres start to stabilize the crack by transferring and sustaining the cracking stress. As the cracks widen with increased loading, the fibres act as a connector, which bridges across the crack and helps slow down the rate of crack opening, thus ensuring the integrity of the composite. Ultimately, the bridging fibres will start to debond from the matrix or rupture and result in the failure of the composite.

Although research works have been carried out on FRCC, most of the works have incorporated only a single type of fibre, such as PVA [2, 3], polyethylene[4], steel [5]

*For correspondence and polypropylene [6] fibres. These fibres are well known among researchers due to their enhancement on mechanical strengths of FRCC, especially tensile and flexural strengths. Most importantly, these fibres have the capacity to induce strain hardening or deflection hardening, which could enhance the ductility of FRCC by causing multiple cracking of the composite. However, direct comparison of the performance of FRCC containing different types of fibre is limited and this necessitates further investigations, especially in cases where properties of fibres are very different.

PVA fibre is one of the most commonly used fibres among researchers. PVA is made by the polymerization of vinyl acetate, creating polyvinyl acetate, which is then converted into powdered form of PVA and extruded as fibres. The unique features of PVA include high aspect ratio, high tensile strength, high modulus of elasticity and relatively low density $\left(1300 \mathrm{~kg} / \mathrm{m}^{3}\right)$ compared with cement matrix $\left(2000-2500 \mathrm{~kg} / \mathrm{m}^{3}\right)$. When PVA fibres are incorporated into cement-based materials, there is a distinct advantage of good interfacial bond with matrix, which enhances the flexural strength of the composite [7]. Other than this, PVA fibre imparts ductility to the cementitious composites by eliminating brittle fracture and inducing multiple micro-cracks, which help prevent catastrophic failure. This ductile behaviour is characterized by high tensile strain capacity (1-5\%) and high energy absorption or toughness to the composites $[8,9]$. Also, this fibre has good resistance to chemical attack, typically in alkaline condition, due to the presence of acetate group $\left(\mathrm{CH}_{3} \mathrm{CO}_{2}^{-}\right)$, 
which absorbs calcium hydroxides [10]. For these reasons, PVA fibre is commonly researched on for the development of FRCC [11-13].

Basalt fibre, on the other hand, is an emerging material in the field of concrete materials due to its excellent mechanical properties. It has much higher tensile strength, modulus of elasticity and density $\left(2650 \mathrm{~kg} / \mathrm{m}^{3}\right)$ compared with PVA fibre. It also has high corrosion resistance and chemical stability, especially in alkaline solution. Generally, basalt fibre is a type of synthetic inorganic fibre that is made from basalt rock, an igneous rock formed from hardened lava. It is manufactured by melting crushed basalt rock around $1400{ }^{\circ} \mathrm{C}$ to molten state and passing through small nozzles to produce continuous filaments of basalt fibres. Preliminary researches carried out have shown that inclusion of basalt fibre is capable of enhancing the mechanical properties of concrete and also has the potential for application as concrete reinforcement [14-16].

Based on these, although both PVA and basalt fibres have distinctive properties, these fibres have the potential to be used in FRCC. Therefore, a comparison in the performance of FRCC that incorporates the PVA and basalt fibres is desired. This should provide more insight and add to the knowledge of fibre utilization in FRCC. Regarding this, the main objective in this research is to investigate the performance of FRCC in terms of the mechanical properties and energy absorption using PVA and basalt fibres at varying fibre dosages.

\section{Materials and methods}

\subsection{Material}

The materials used in this research are ordinary Portland cement (OPC), class-F fly ash, river sand with particle size below $1.18 \mathrm{~mm}$, water and polycarboxylate-ether-based superplasticizer (SP), as well as the PVA and basalt fibres (figure 1 and figure 2). Table 1 shows the general properties of the PVA and basalt fibres as provided by the supplier of materials.

\subsection{Specimen preparation}

The mixture proportion of FRCC in this research is listed in table 2. In order to assess the effects of fibre type and volume fraction on FRCC, the binder content, water to binder (w/b) ratio and dosage of SP were kept constant. The inclusion of high volume of fly ash was to limit the cement content as well as to achieve sufficient workability for the mixing of fibres. The volume fraction of PVA and basalt fibres was varied at $0 \%, 1.0 \%, 1.5 \%$ and $2.0 \%$. Based on the most optimum mix from PVA- and basalt-FRCC, an additional mix HBP with hybridization of $1.5 \%$ PVA and $1.5 \%$ basalt fibres was also included for comparison with mixes consisting of single-type fibres.

\subsection{Casting and curing}

The materials were mixed in a mortar-mixing machine and the mixing sequence shown here was adopted to produce FRCC in this investigation:

i. Dry mixing of powder material (OPC, fly ash and fine aggregate) for $1 \mathrm{~min}$.

ii. Addition and mixing of liquid material (water and $\mathrm{SP}$ ) in low revolution for $1 \mathrm{~min}$ and high revolution for $1 \mathrm{~min}$.

iii. Addition and mixing of fibres until the fresh FRCC is homogenous and no fibre balling is observed.

The fresh FRCC was then cast into oiled steel moulds and stored in a sealed room for 1 day. After this, the specimens were demoulded and cured in water tank until testing age of 28 days.

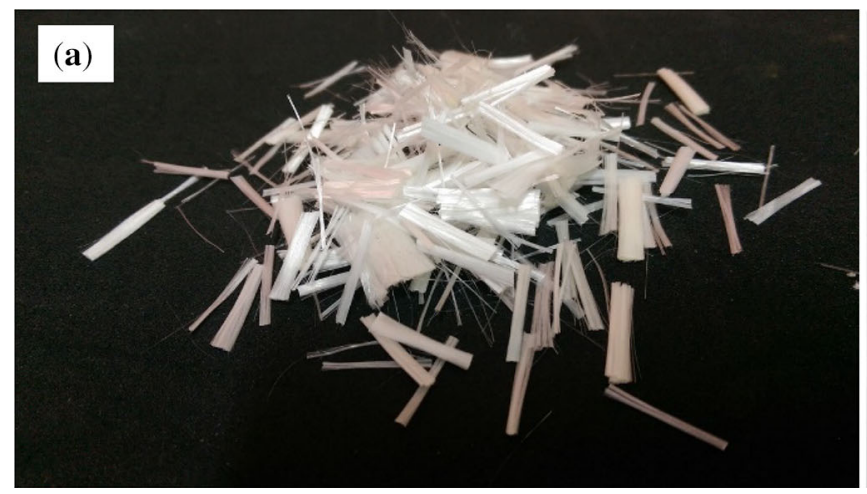

(b)

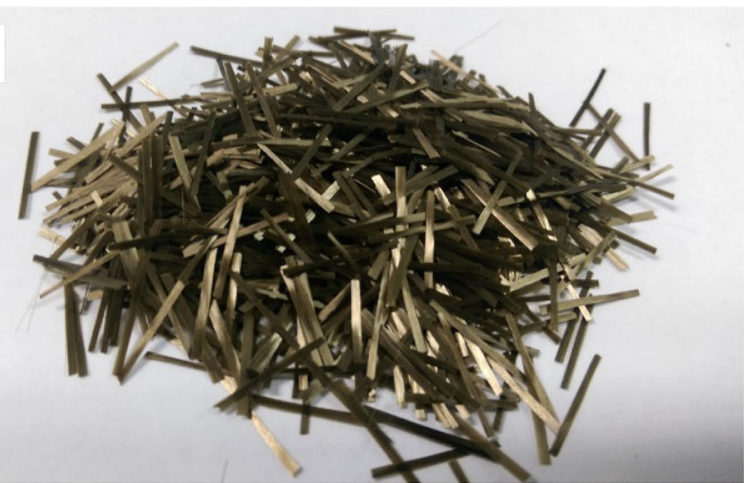

Figure 1. (a) PVA fibre and (b) basalt fibre. 

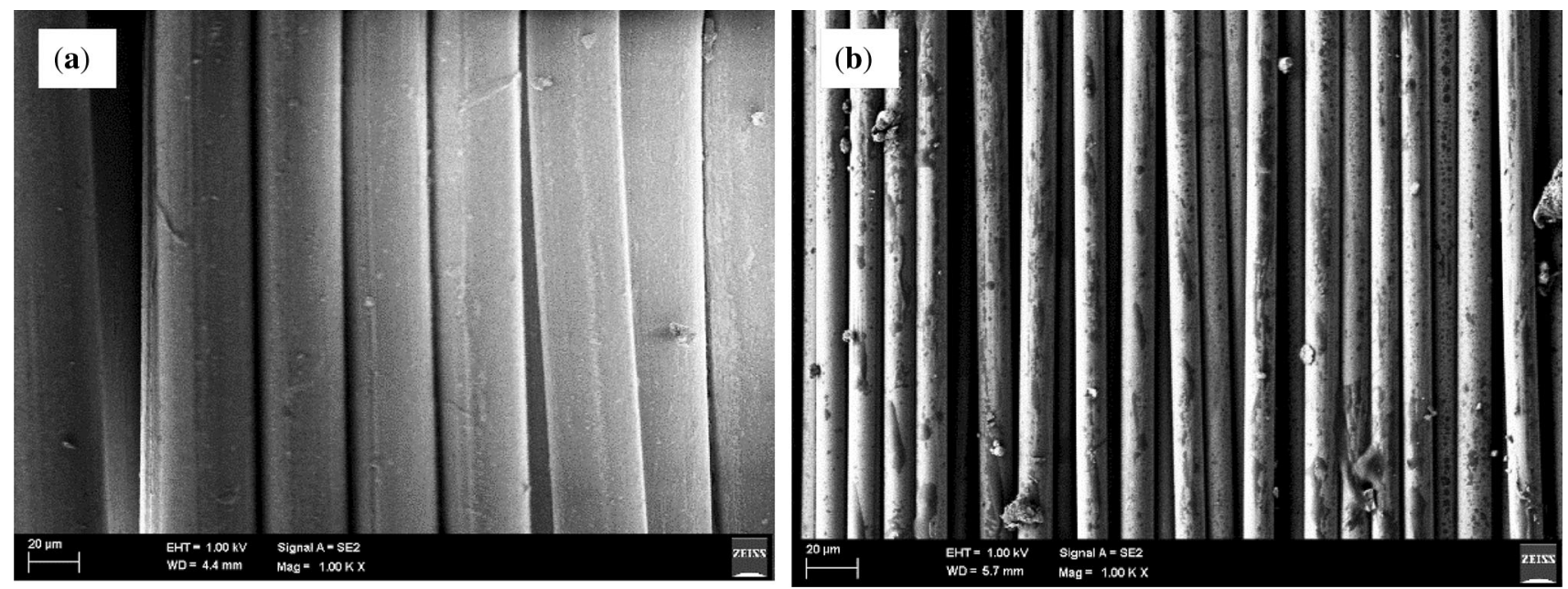

Figure 2. Scanning electron microscope (SEM) image: (a) PVA fibre and (b) basalt fibre.

Table 1. Properties of PVA and basalt fibres.

\begin{tabular}{lcc}
\hline Fibre properties & PVA fibre & Basalt fibre \\
\hline Tensile strength $(\mathrm{GPa})$ & 1.6 & $4.15-4.80$ \\
Modulus of elasticity $(\mathrm{GPa})$ & 41 & $100-110$ \\
Cut length $(\mathrm{mm})$ & 12 & 12 \\
Diameter $(\mu \mathrm{m})$ & 40 & 12 \\
Aspect ratio & 300 & 1000 \\
Specific gravity & 1.3 & 2.65 \\
Cross-sectional shape & Circular & Circular \\
\hline
\end{tabular}

\subsection{Testing method}

2.4a Workability test: Flow table test was conducted to assess the workability of the fresh FRCC based on ASTM C1437-15 [17]. The spread diameter of the fresh FRCC on the flow table was reported using the average of two measurements.

2.4b Compressive and splitting tensile strength test: The compressive strength of $50 \times 50 \times 50 \mathrm{~mm}^{3}$ cube specimens was determined according to BS EN 12390-3:2009 [18] while the splitting tensile strength test was carried out on cylindrical specimens with dimension of $100 \mathrm{~mm}$ diameter and $200 \mathrm{~mm}$ height in accordance with BS EN 12390-6:2009 [19]. The compressive and splitting tensile strength results were reported based on an average of three readings. The machine used was an ELE compression machine with a load capacity of $2000 \mathrm{kN}$.

2.4c 4-point bending test: In this investigation, the 4-point bending test was carried out on specimens with dimensions of $500 \mathrm{~mm} \times 75 \mathrm{~mm} \times 16 \mathrm{~mm}$, modified based on previous research $[3,20]$ to suit the testing facility available in the laboratory (figure 3 ). In addition, as the material is being developed to serve as potential thin overlay repair material, this dimension of specimen was selected for evaluation of the flexural performance. The machine used for the 4-point bending test was an INSTRON displacement-controlled testing machine having a load capacity of $100 \mathrm{kN}$. From the 4-point bending test, the energy absorption of the specimens was determined as an indication of the ductility of the FRCC specimens. This was done based on the flexural loaddeflection curve, whereby the energy absorption was determined using the total area under the curve up to the point where the load was reduced to $50 \%$ of the ultimate

Table 2. Mixture proportion of FRCC.

\begin{tabular}{lccccccc}
\hline Specimen & Cement $\left(\mathrm{kg} / \mathrm{m}^{3}\right)$ & Fly ash $\left(\mathrm{kg} / \mathrm{m}^{3}\right)$ & Sand $\left(\mathrm{kg} / \mathrm{m}^{3}\right)$ & Water $\left(\mathrm{kg} / \mathrm{m}^{3}\right)$ & $\mathrm{SP}\left(\mathrm{kg} / \mathrm{m}^{3}\right)$ & PVA fibre $\left(\mathrm{kg} / \mathrm{m}^{3}\right)$ & Basalt fibre $\left(\mathrm{kg} / \mathrm{m}^{3}\right)$ \\
\hline C-0 & 540 & 560 & 665 & 385 & 2.75 & - & - \\
B-1.0 & 540 & 560 & 639 & 385 & 2.75 & - & - \\
B-1.5 & 540 & 560 & 626 & 385 & 2.75 & - & - \\
B-2.0 & 540 & 560 & 613 & 385 & 2.75 & 26.50 & - \\
P-1.0 & 540 & 560 & 639 & 385 & 2.75 & 13.00 & - \\
P-1.5 & 540 & 560 & 626 & 385 & 2.75 & 19.50 & - \\
P-2.0 & 540 & 560 & 613 & 385 & 2.75 & 26.00 & 19.50 \\
HBP & 540 & 560 & 587 & 385 & 2.75 & & 39.75 \\
\hline
\end{tabular}




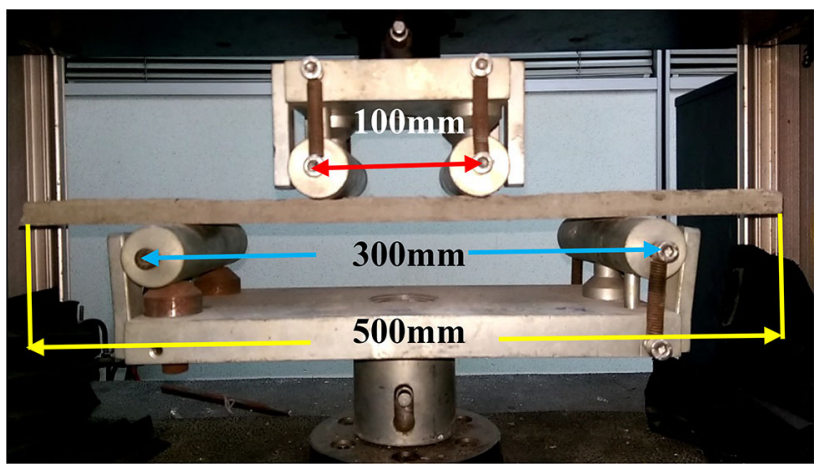

Figure 3. Four-point bending test.

Table 3. Compressive and tensile strength of FRCC specimens at 28 days strength.

\begin{tabular}{lcccc}
\hline Specimens & $\begin{array}{c}\text { Compressive } \\
\text { strength } \\
(\mathrm{MPa})\end{array}$ & $\begin{array}{c}\text { Percentage } \\
\text { difference } \\
(\%)\end{array}$ & $\begin{array}{c}\text { Tensile } \\
\text { strength } \\
(\mathrm{MPa})\end{array}$ & $\begin{array}{c}\text { Percentage } \\
\text { difference } \\
(\%)\end{array}$ \\
\hline C-0 & 53.5 & - & 2.75 & - \\
B-1.0 & 53.4 & +0.2 & 4.55 & +65.6 \\
B-1.5 & 59.8 & +11.8 & 4.65 & +69.1 \\
B-2.0 & 54.8 & +2.4 & 5.00 & +81.8 \\
P-1.0 & 52.9 & -1.1 & 4.70 & +70.9 \\
P-1.5 & 47.7 & -10.8 & 4.90 & +78.2 \\
P-2.0 & 52.0 & -2.8 & 5.40 & +96.4 \\
HBP & 54.8 & +2.4 & 5.40 & +96.4 \\
\hline
\end{tabular}

load. This method of determination was also adopted by Pakravan et al [9].

\section{Results and discussion}

\subsection{Workability}

Figure 4 shows that the workability of basalt-FRCC and PVA-FRCC decreases with increasing fibre volume fraction. Similarly, based on previous studies, regardless of the type of fibre used, the workability of FRCC decreased with higher fibre dosage $[10,21]$. This can be explained by the increase of total fibre surface area along with the fibre dosage. Hence, the FRCC required higher volume of matrix to coat the fibres, which resulted in the reduction in workability. The specimen with the least workability was the HBP mix with only $129.5 \mathrm{~mm}$ spread diameter, which was $45.5 \%$ less than the control C-0 $(237.5 \mathrm{~mm})$ as the former contained the highest total fibre volume fraction of $3.0 \%$. This caused the fresh hybrid FRCC to have the highest fibre surface area required to be coated by matrix.

When assessing the effect of fibre type, it was found that the workability of basalt-FRCC decreased in the range of

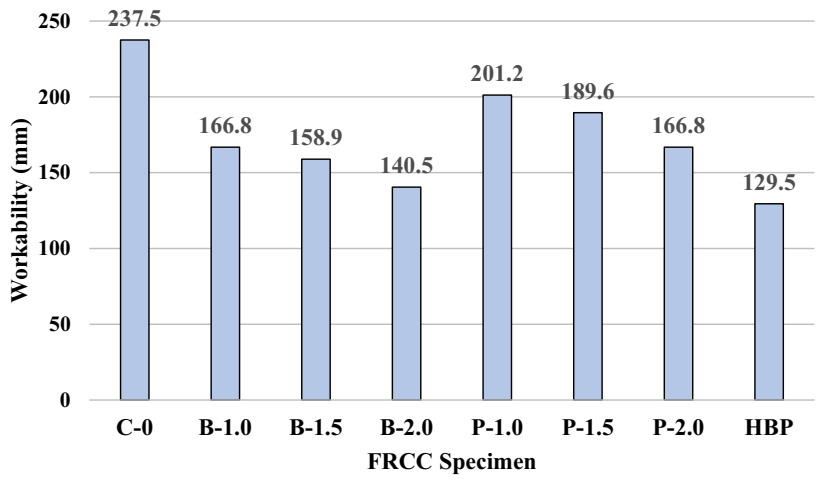

Figure 4. Workability of FRCC specimens.

29.8-40.8\% whereas that of PVA-FRCC reduced 15.3-29.8\% when compared with C-0. This shows that the extent of workability reduction in FRCC containing basalt fibre is greater than that for PVA fibre. According to Bentur and Mindess [1], the presence of fibre could induce stiffening effect of the matrix and the higher the stiffness of the fibres, the greater the reduction of workability. In this case, the stiffening effect of the basalt fibre could be more intense than that of PVA fibre in the FRCC due to the higher elastic modulus and stiffness of the former. Besides this, as the aspect ratio of the basalt fibre used was higher than that of the corresponding PVA fibre, there was an increase of surface area of fibres, which also contributed towards the decrease in the workability of the FRCC.

\subsection{Compressive strength}

In the past research works, the effect of fibre inclusion on compressive strength is inconclusive as there were contrasting observations made; there were researchers who reported improvement in the compressive strength with certain dosage of fibre addition whereas on the other hand there were findings of lowering compressive strength with fibre addition [22-25]. Table 3 shows that the effect of fibre on the compressive strength of the FRCC mixes was minimal as the percentage difference was only $\pm 12 \%$. Nevertheless, the result shows that the effect of basalt fibre in enhancing the compressive strength of FRCC is more pronounced compared with the corresponding PVA fibre. Likewise, Jiang et al [26] reported that the concrete reinforced by basalt fibre was beneficial for enhancing the 28-day compressive strength and Hossain et al [27] found out that the inclusion of PVA fibre could reduce the compressive strength by up to $15 \%$. This could be due to the main chemical composition of basalt fibre, which contained $\mathrm{SiO}_{2}$ (48-59\%), $\mathrm{Al}_{2} \mathrm{O}_{3}(15-18 \%)$ and $\mathrm{Fe}_{2} \mathrm{O}_{3}+\mathrm{FeO}(7-$ $12 \%$ ), which is similar to the cement matrix. It is also possible that the higher modulus of basalt fibre causes the basalt-FRCC to be stiffer and hence it exhibits higher 
compressive strength. On the other hand, it was found that P-1.5 had higher reduction in compressive strength than P-2.0 and this could be due to the improper compaction for P-1.5 specimens, which caused the presence of more voids. On the other hand, there was only a slight increment of $2.4 \%$ in the compressive strength of HBP mix. This suggested that the compressive strength enhancement from basalt fibre could offset the strength reduction caused by the PVA fibre. It should be noted that the mix HBP had lower compressive strength compared with the mix B-1.5, which was likely due to the difficulty in compaction due to increased fibre content [24].

\subsection{Tensile strength}

When fibres are added, the tensile load sustained by the brittle matrix is transferred to the fibres and this increases the tensile strength of composites. In this study, significant improvement in FRCC tensile strength was observed after fibre addition. Also, the enhancement grew along with the dosage of fibre. As shown in table 3, similar range of increment in the tensile strength was observed for basaltFRCC (65.6-81.8\%), PVA-FRCC (70.9-96.4\%) and hybrid specimen $(96.4 \%)$. Commonly, presence of fibre increases concrete tensile strength [28-30]. For basalt-fibrereinforced concrete, Jiang et al [26] reported that low dosage $(0.05-0.5 \%)$ of basalt fibre was able to increase the splitting tensile strength by about $14.1-25.5 \%$ whereas Ayub et al [31] reported that high dosage (1-3\%) of basalt fibre could enhance the tensile strength significantly by up to $85 \%$. Noushini et al [30] found out that the tensile strength of concrete was increased by about $27 \%$ with addition of PVA fibre volume of up to $0.5 \%$. Moreover, even for polypropylene-fibre-reinforced engineered cementitious composites (ECC), Said and Razak [28] reported that the ultimate tensile strength and the tensile capacity were increased along with fibre dosage.

Even though the basalt fibre used has higher tensile strength and aspect ratio than those of PVA fibre, the FRCC tensile strength enhancement was only marginally higher than that of PVA fibre. This could be due to the strength reduction coefficient of basalt fibre, which was reported to be higher than that of PVA fibre [32]. For short fibre length from 8 to $12 \mathrm{~mm}$, it is assumed that both basalt and PVA fibres used in this research are randomly orientated in the matrix [1]. Hence, based on the single fibre pull-out test done by Choi and Lee [32], the tensile strength of basalt fibre was reported to be lower than that of PVA fibre at different inclination angles. Therefore, PVA fibre will have higher effective tensile strength than basalt fibre when embedded in the cement matrix. As a result, PVA fibre exhibits greater resistance when pulled off from the matrix, contributing to slightly higher tensile strength for the composite. In terms of the effect of hybrid fibres inclusion, the enhancement of tensile strength was similar to that of
Table 4. First crack load, post-peak load and flexural strength of FRCC specimens.

\begin{tabular}{lcccc}
\hline & $\begin{array}{c}\text { First } \\
\text { crack load } \\
(\mathrm{N})\end{array}$ & $\begin{array}{c}\text { Post-peak } \\
\text { load (N) }\end{array}$ & $\begin{array}{c}\text { Flexural } \\
\text { strength } \\
(\mathrm{MPa})\end{array}$ & $\begin{array}{c}\text { Percentage } \\
\text { difference } \\
(\%)\end{array}$ \\
\hline C-0 & 374.23 & - & 5.8 & - \\
B-1.0 & 457.82 & - & 7.2 & +24.1 \\
B-1.5 & 520.41 & - & 8.1 & +39.7 \\
B-2.0 & 544.86 & - & 8.5 & +46.6 \\
P-1.0 & 396.69 & 361.46 & 6.2 & +6.9 \\
P-1.5 & 370.59 & 443.82 & 6.9 & +19.0 \\
P-2.0 & 372.81 & 464.84 & 7.3 & +25.9 \\
HBP & 461.27 & 414.65 & 7.2 & +24.1 \\
\hline
\end{tabular}

the mix P-2.0. This could be due to effect of PVA fibre, which was more dominant in enhancement of tensile strength, whereas the basalt fibre had minor contribution to the enhancement of tensile strength.

\subsection{Flexural strength and energy absorption}

Generally, fibres can improve flexural strength, sustain additional loading after first crack and prevent instantaneous failure after the first crack load is exceeded, all of which contribute towards imparting ductility to the concrete $[33,34]$. However, in this investigation, it was observed that only the FRCC containing PVA fibre exhibited all of these characteristics, whereas basalt-FRCC demonstrated only increase in flexural strength.

Table 4 shows that higher fibre content provides better enhancement in the flexural strength and this could allow more load to be transferred and sustained by the fibres. Also, Pakravan et al [9] suggested that higher fibre content contributes to higher chemical bond to the matrix, leading to better enhancement of ultimate strength. It was noticed that basalt fibre had better enhancement than PVA fibre in flexural strength of FRCC. The result shows that the enhancement of flexural strength from basalt fibre is 24.1-46.6\%, PVA fibre is 6.9-25.9\% and hybrid of PVAbasalt fibres is $24.1 \%$ in this research. This might be due to the higher chemical bond to the cement matrix provided by basalt fibre, causing higher flexural strength. Shafiq et al [33] similarly noted that the flexural strength of concrete increased when both basalt and PVA fibres dosages were increased but basalt fibre had better enhancement in flexural strength corresponding to PVA fibre. Although HBP contained the highest fibre content, only similar improvement in the flexural strength as that of B-1.0 was found and this could be explained by the improper fibre dispersion and difficulty in compaction due to lower workability. As a result, the lower efficiency did not significantly improve the flexural strength. 


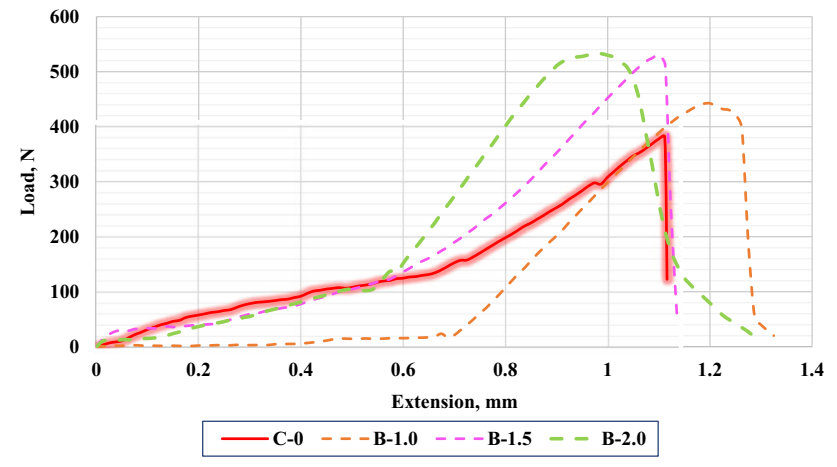

Figure 5. Load-extension curve of control and basalt-FRCC specimens.

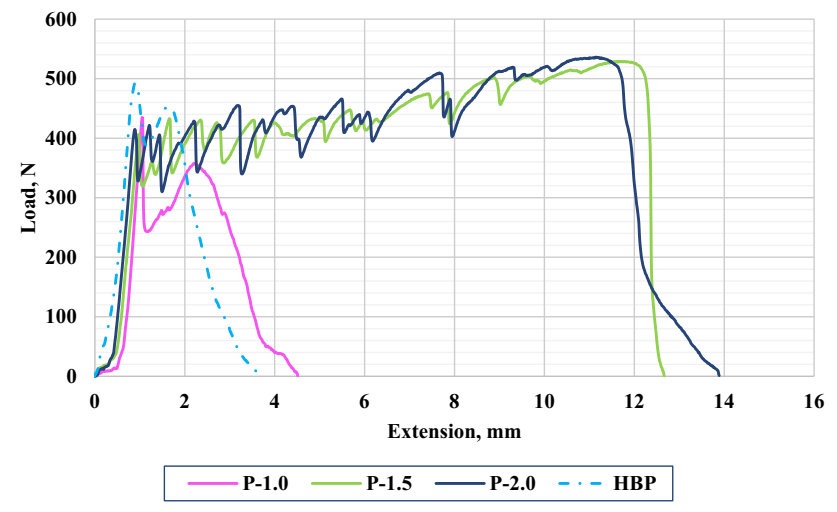

Figure 6. Load-extension curve of PVA-FRCC and hybrid specimens.

On the other hand, table 4 indicates that the presence of both first crack and post-peak loads was only found in FRCC with PVA fibre, including the hybrid specimens. It can be observed in figure 5 that $\mathrm{C}-0$ and basalt-FRCC exhibit only a single peak in the load-deflection curve. However, for the case of PVA-FRCC and HBP in figure 6, more than one peak is noticed. This shows that the PVA fibre plays a major role in post-cracking stage whereas basalt-fibre has no influence on the post-cracking stage. This could be attributed to the rupturing of the basalt fibres as soon as the first cracking occurred and the first peak load was attained. While the inclusion of basalt fibres was found to increase the first cracking load, PVA fibre had little influence compared with the control specimen as shown in the ratio of first cracking load corresponding to $\mathrm{C}-0$, which is illustrated in figure 7. Similar findings also reported that the types of fibre such as polyethylene and PVA had little influence during pre-cracking stage and the first crack load was not affected by fibre dosage [35, 36]. For the HBP specimen, the presence of basalt fibres could be the likely reason for increase in the first peak load, which was found to be about $24.1 \%$. Additionally, as seen in figure 7 , the rise in fibre content increased the ratio of post-peak load to first crack load from 0.91 to 1.25 in PVA-FRCC. According to Pakravan et al [9], this ratio reflects the effectiveness of fibres on the strength of the composite as higher fibre content indicates that more fibres are able to sustain the loading after first crack, resulting in better load bearing effect. However, HBP had lower ratio than that of P-1.0 despite its high fibre content and as mentioned, this was likely due to the difficulty in fibre dispersion, causing ineffective load transfer to the fibre.

On observing the load-extension curves in figure 5 and figure 6 , different behaviours are observed based on the types of fibre and its dosages. The failure mode as shown in figure 8 corresponds well to the load-extension curves. As

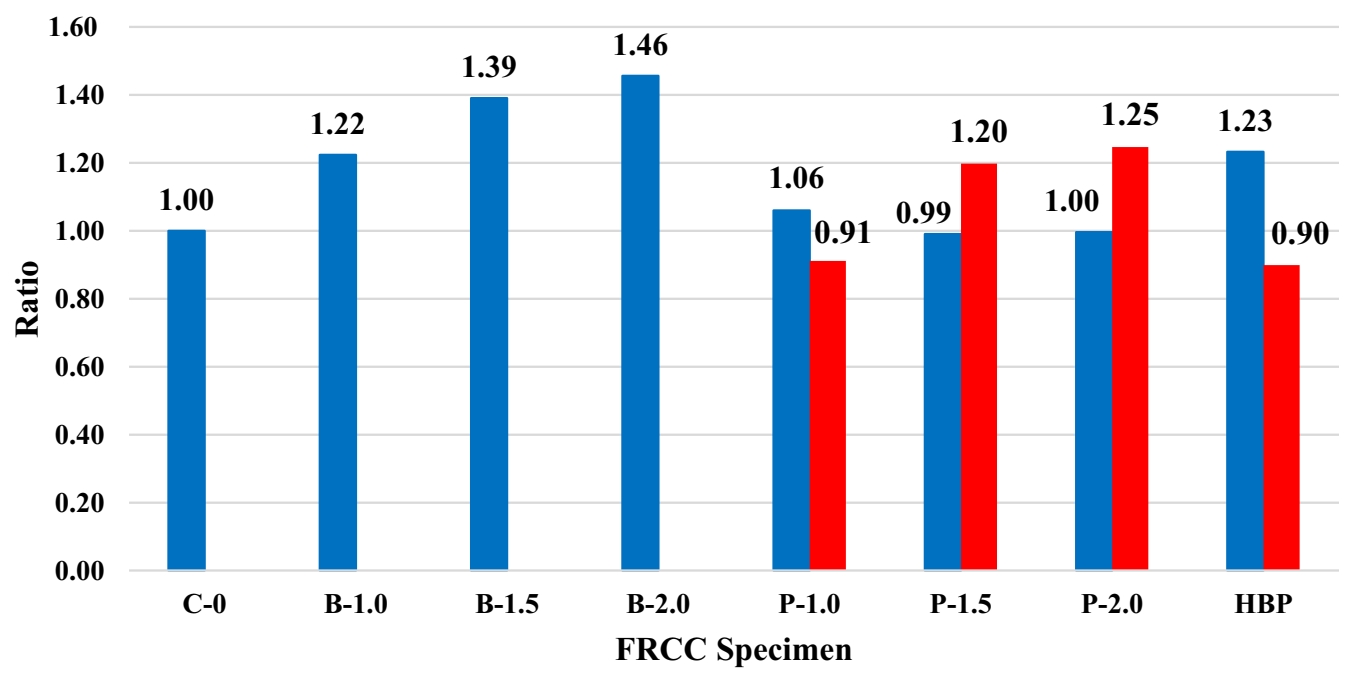

$\square$ Ratio of first crack load respect to C-0 $\square$ Ratio of post crack load to first crack load

Figure 7. Ratio of first crack load to $\mathrm{C}-0$ and ratio of post-crack load to first crack load. 

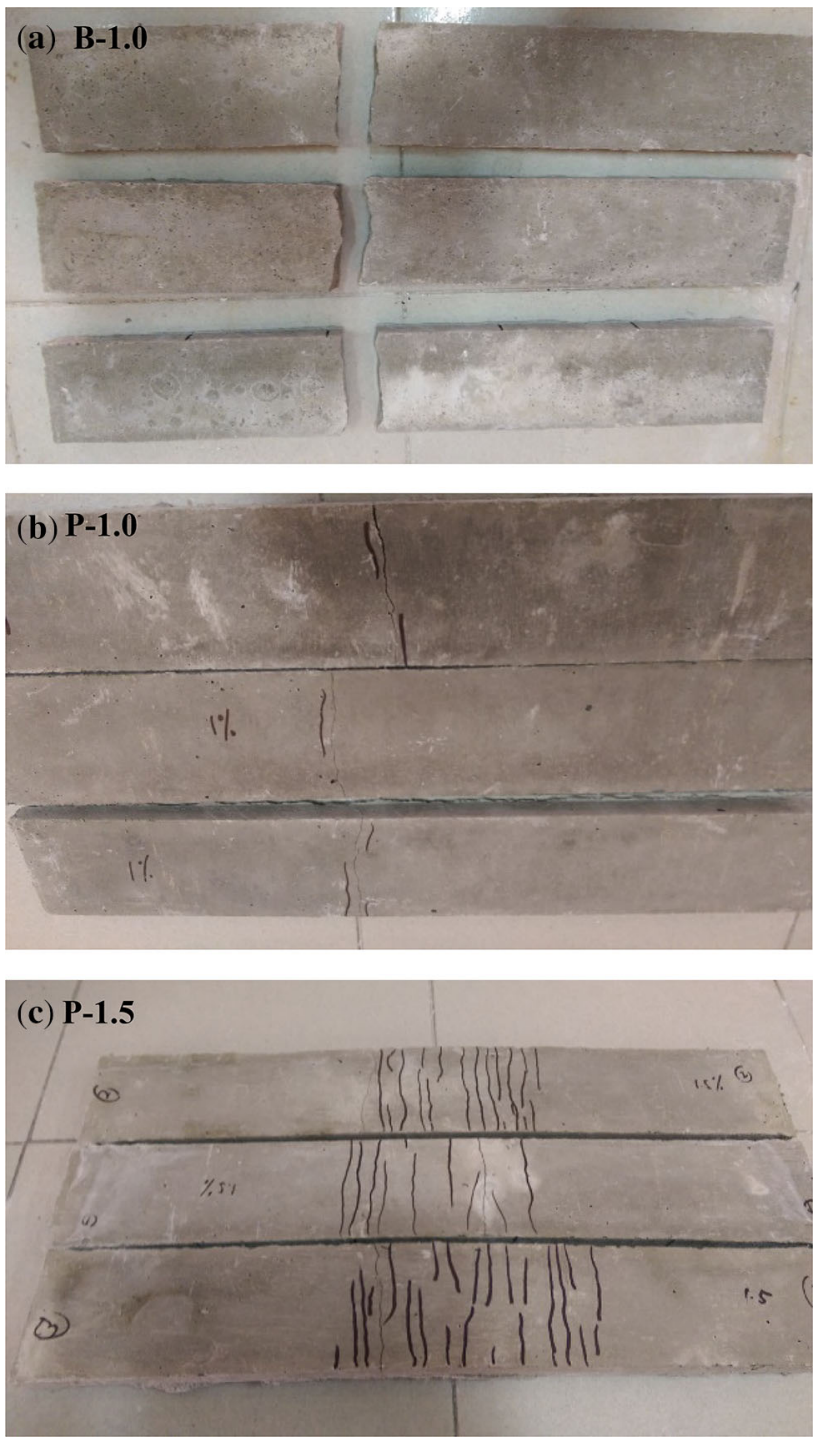

Figure 8. Crack pattern of failed FRCC specimen: (a) B-1.0, (b) P-1.0 and (c) P-1.5.

expected, the control specimen failed immediately and ruptured into two halves after the first crack load was reached. In the case of basalt-FRCC, its failure mode was similar to that of $\mathrm{C}-0$ for specimens with different fibre dosages, indicating insignificant contribution to postcracking behaviour. It is likely that due to the higher elastic modulus of basalt fibre, premature failure at lower displacement occurred after the first crack load was attained. As mentioned, this can be supported by the fact that high chemical bond and frictional bond strength existed [32], which caused the basalt fibres to rupture and hence the specimen split into two halves upon reaching the first crack load (figure 8a). On the other hand, the lower-modulus PVA fibre allowed more dowel action after first cracking to bridge across the crack. However, only P-1.5 and P-2.0 specimens exhibited deflection hardening behaviour by having higher post-peak load than their respective first

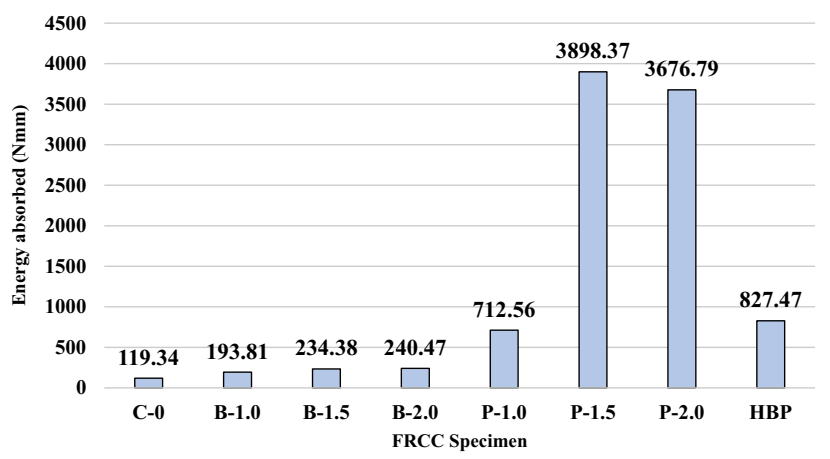

Figure 9. Energy absorption of FRCC specimen.

crack load (table 4) [37]. Correspondingly, the shape of load-displacement curves of specimens P-1.5 and P-2.0 is in plastic yielding [37] as the load is redistributed between the matrix and bridging fibres. The redistribution of additional loading caused multiple crackings (figure 8c) of the FRCC [37]. This also indicates that the fibre dosage of $1.5 \%$ and $2.0 \%$ has surpassed the critical fibre volume. According to Bentur and Mindess [1], in order to obtain strain hardening or deflection hardening FRCC, the fibre content must exceed the critical fibre volume in order to sufficiently sustain the loading and bridge the cracked matrix. In this investigation, it was found that the fibre dosage of $1.0 \%$ in the P-1.0 specimens did not have sufficient fibre volume to provide strengthening and bridging effect in post-cracking stage. As a result, P-1.0 had lower post-peak load than first crack load by displaying deflection softening behaviour and exhibited only single crack failure as shown in figure $8 \mathrm{~b}$. Meanwhile, although HBP specimen contained $1.5 \%$ PVA fibre volume, there was no deflection hardening behaviour and similar localized crack failure as P-1.0 specimen was found. This could be due to the high total fibre dosage in HBP, causing compaction to be difficult, which results in ineffective crack bridging from PVA fibre.

The energy absorption in FRCC is related to the dissipation of energy from flexure loading through de-bonding and pull-out of fibres during cracks bridging [1, 38]. As energy absorption is calculated based on the area under the load-extension curve, larger area under load-deflection curve indicates higher energy absorption and can be correlated to better ductility. As expected, the inclusion of fibre showed significant enhancement in the calculated energy absorption of FRCC as shown in figure 9. Due to the presence of post-cracking strength of PVA-FRCC and HBP specimens, the improvement in energy absorption (497.1-3166.6\%) was superior compared with the corresponding basalt-FRCC (62.4-101.5\%) specimens. Overall, the energy absorption gradually increased with fibre dosage except in the case of P-2.0 and HBP. The slight decrease in energy absorbed in P-2.0 can be explained by the fact that fibre dosage at $1.5 \%$ had better fibre dispersion, resulting in 
more effective and efficient crack bridging to dissipate the energy from flexure loading. On the other hand, the higher dosage of fibres could induce voids, which might affect the energy absorption ability. This phenomenon was also reported in the research of Pakravan et al [9], where the energy absorption ability with $2.0 \%$ PVA fibre was lower than $1.6 \%$. Additionally, since the HBP specimen did not exhibit deflection hardening behaviour, it is expected to possess lower energy absorption compared with the P-1.5 specimen. Also, as described earlier, the basalt fibre has higher high chemical bond and frictional bond strength to the cementitious matrix [32] compared with PVA fibre. When these bonding strengths are higher, the interfacial fibre-matrix stress increases, causing the fibres to rupture instead of undergoing effective bridging upon cracking. Although HBP had higher PVA fibre dosage than P-1.0, figure 9 shows that the energy absorption of HBP is only slightly better (16.1\%) than P-1.0. This is possibly due to the congestion of fibres in the HBP mix, causing the extra $0.5 \%$ volume of PVA fibre to be ineffective in carrying extra load.

In short, although basalt fibre had better enhancement in the flexural strength, the inclusion of PVA fibre outperformed basalt fibre in terms of the overall flexural behaviour due to presence of post-cracking strength and deflection hardening behaviour. Hence, PVA-FRCC can be considered to be more ductile than basalt-FRCC.

\section{Conclusion}

This experimental study focused on the development of FRCC using PVA, basalt and hybrid PVA-basalt fibres. Based on this discussion, the following conclusion could be drawn:

a. Regardless of fibre type, the workability of FRCC decreased with increasing fibre dosage and the reduction effect was more severe with basalt fibre.

b. The effect of both PVA and basalt fibre in the 28-day compressive strength is insignificant and inconsistent along with the fibre dosage. However, testing the compressive strength at higher age of 90 and 180 days together with microstructure analysis is recommended.

c. The splitting tensile strength of FRCC increased along with fibre dosage and the enhancements from both fibres are similar.

d. The ultimate flexural strength of FRCC improved with increasing fibre dosage (up to $2 \%$ ) and it was slightly higher in basalt-FRCC. However, the hybrid FRCC with total 3\% fibre dosage had lower flexural strength as compared with PVA- and basalt-FRCC with $2 \%$ fibre content.

e. The use of basalt fibre was found to enhance first crack load of the FRCC whereas little effect was observed in the case of the PVA fibres. On the other hand, the PVAFRCC outperformed the basalt-FRCC, especially with the PVA fibre dosage of $1.5 \%$, in terms of alteration to a more ductile failure mode, enhancement of the post-peak strength and increase in the energy absorption of the composite.

Based on the studied properties of FRCC, it can be concluded that the use of PVA fibre is more beneficial in FRCC given its ability to impart ductility, which is of prime importance in the use of FRCC.

\section{Acknowledgement}

The financial support provided by University of Malaya under the grants PG163-2015A and GPF034A-2018 is gratefully acknowledged.

\section{References}

[1] Bentur A and Mindess S 2007 Fibre reinforced cementitious composites, 2nd ed. NY: Taylor \& Francis

[2] Yu J and Leung C K Y 2017 Strength improvement of strainhardening cementitious composites with ultrahigh-volume fly ash. J. Mater. Civ. Eng. 29(9): 8

[3] Pan Z F, Wu C, Liu J Z, Wang W and Liu J W 2015 Study on mechanical properties of cost-effective polyvinyl alcohol engineered cementitious composites (PVA-ECC). Constr. Build. Mater. 78: 397-404

[4] Choi J I, Lee B Y, Ranade R, Li V C and Lee Y 2016 Ultrahigh-ductile behavior of a polyethylene fiber-reinforced alkali-activated slag-based composite. Cement Concr. Compos. 70(Suppl. C): 153-158

[5] Tufekci M M and Gokce A 2017 Development of heavyweight high performance fiber reinforced cementitious composites (HPFRCC)—part I: mechanical properties. Constr. Build. Mater. 148: 559-570

[6] Mastali M, Dalvand A and Fakharifar M 2016 Statistical variations in the impact resistance and mechanical properties of polypropylene fiber reinforced self-compacting concrete. Comput. Concr. 18(1): 113-137

[7] Khan M I, Abbas Y M and Fares G 2017 Review of high and ultrahigh performance cementitious composites incorporating various combinations of fibers and ultrafines. J. King Saud Univ. Eng. Sci. 29(4): 339-347

[8] Meng D, Huang T, Zhang Y X and Lee C K 2017 Mechanical behaviour of a polyvinyl alcohol fibre reinforced engineered cementitious composite (PVA-ECC) using local ingredients. Constr. Build. Mater. 141(Suppl. C): 259-270

[9] Pakravan H R, Jamshidi M and Latifi M 2018 The effect of hydrophilic (polyvinyl alcohol) fiber content on the flexural behavior of engineered cementitious composites (ECC). J. Text. Inst. 109(1): 79-84

[10] Li M and Li V C 2013 Rheology, fiber dispersion, and robust properties of Engineered Cementitious Composites. Mater. Struct. 46(3): 405-420

[11] Magalhães M D S, Toledo Filho R D and Fairbairn E D M R 2015 Thermal stability of PVA fiber strain hardening cement-based composites. Constr. Build. Mater. 94(Suppl. C): $437-447$ 
[12] Wang L, Zhou S H, Shi Y, Tang S W and Chen E 2017 Effect of silica fume and PVA fiber on the abrasion resistance and volume stability of concrete. Compos. Part B: Eng. 130(Suppl. C): 28-37

[13] Xu F, Deng X, Peng C, Zhu J and Chen J 2017 Mix design and flexural toughness of PVA fiber reinforced fly ashgeopolymer composites. Constr. Build. Mater. 150(Supplement C): $179-189$.

[14] Ma J X, Zhang M and Zhao G 2013 Experimental research on basalt fiber reinforced cementitious composites. Appl. Mech. Mater. 253-255: 533-536

[15] Ayub T, Shafiq N and Nuruddin M F 2014 Effect of chopped basalt fibers on the mechanical properties and microstructure of high performance fiber reinforced concrete. Adv. Mater. Sci. Eng. 2014: 14

[16] Branston J, Das S, Kenno S Y and Taylor C 2016 Mechanical behaviour of basalt fibre reinforced concrete. Constr. Build. Mater. 124(Supplement C): 878-886

[17] ASTM 2015 Standard test method for flow of hydraulic cement mortar. ASTM C1437-15. West Conshohocken, PA: ASTM International

[18] BSI 2009 Testing hardened concrete: compressive strength of test specimens. BS EN 12390-3:2009. London: BSI

[19] BSI 2009 Testing hardened concrete: tensile splitting strength of test specimens. BS EN 12390-6:2009. London: BSI

[20] Chandrangsu K and Naaman A E 2003 Comparison of tensile and bending response of three high performance fiber reinforced cement composites. In: Naaman A E and Reinhardt $\mathrm{H}$ $\mathrm{W}$ (Eds.) Proceedings of the 4th International RILEM Workshop on High Performance Fiber-Reinforced Cement Composites (HPFRCC4). RILEM Publications SARL, Ann Arbor, Michigan, pp. 259-274

[21] Figueiredo A D D and Ceccato M R 2015 Workability analysis of steel fiber reinforced concrete using slump and Ve-Be test. Mater. Res. 18(6): 1284-1290

[22] Sivakumar A and Santhanam M 2007 Mechanical properties of high strength concrete reinforced with metallic and nonmetallic fibres. Cement Concr. Compos. 29(8): 603-608

[23] Grantham M, Basheer P A M, Magee B and Soutsos M 2014 Concrete solutions. CRC Press, London, UK

[24] Yusof M A, Nor N M, Zain M F M, Peng N C, Ismail A, Sohaimi R M and Zaidi A M A 2011 Mechanical properties of hybrid steel fibre reinforced concrete with different aspect ratio. Aust. J. Basic Appl. Sci. 5(7): 159-166

[25] Fakharifar M, Dalvand A, Arezoumandi M, Sharbatdar M K and Chen G 2014 A. Kheyroddin, Mechanical properties of high performance fiber reinforced cementitious composites. Constr. Build. Mater. 71(Supplement C): 510-520.

[26] Jiang C, Fan K, Wu F and Chen D 2014 Experimental study on the mechanical properties and microstructure of chopped basalt fibre reinforced concrete. Mater. Des. 58(Suppl. C): 187-193

[27] Hossain K M A, Lachemi M, Sammour M and Sonebi M 2013 Strength and fracture energy characteristics of selfconsolidating concrete incorporating polyvinyl alcohol, steel and hybrid fibres. Constr. Build. Mater. 45(Supplement C): $20-29$

[28] Said S H and Razak H A 2015 The effect of synthetic polyethylene fiber on the strain hardening behavior of engineered cementitious composite (ECC). Mater. Des. 86: $447-457$

[29] Li Z X, Li C H, Shi Y D and Zhou X J 2017 Experimental investigation on mechanical properties of Hybrid Fibre Reinforced Concrete. Constr. Build. Mater. 157(Supplement C): $930-942$

[30] Noushini A, Vessalas K and Samali B 2013 Flexural and tensile characteristics of polyvinyl alcohol fibre reinforced concrete (PVA-FRC). In: Proceedings of the Thirteenth East Asia-Pacific Conference on Structural Engineering and Construction (EASEC-13), Sapporo, Japan

[31] Ayub T, Shafiq N and Nuruddin M F 2014 Mechanical properties of high-performance concrete reinforced with basalt fibers. Proc. Eng. 77: 131-139

[32] Choi J I and Lee B Y 2015 Bonding properties of basalt fiber and strength reduction according to fiber orientation. Materials 8(10): 6719-6727

[33] Shafiq N, Ayub T and Khan S U 2016 Investigating the performance of PVA and basalt fibre reinforced beams subjected to flexural action. Compos. Struct. 153(Supplement C): $30-41$

[34] Lee J H, Cho B and Choi E 2017 Flexural capacity of fiber reinforced concrete with a consideration of concrete strength and fiber content. Constr. Build. Mater. 138(Supplement C): 222-231

[35] Said S H, Razak H A and Othman I 2015 Flexural behavior of engineered cementitious composite (ECC) slabs with polyvinyl alcohol fibers. Constr. Build. Mater. 75(Supplement C): 176-188

[36] Lin C, Kayali O, Morozov E V and Sharp D J 2014 Influence of fibre type on flexural behaviour of self-compacting fibre reinforced cementitious composites. Cement Concr. Compos. 51(Supplement C): 27-37

[37] Aveston A, Cooper G A and Kelly A 1971 The properties of fibre composites. In: Conference Proceedings, National Physical Laboratories, IPC. London: Science and Technology Press, pp. 15-24

[38] Yoo D Y, Lee J H and Yoon Y S 2013 Effect of fiber content on mechanical and fracture properties of ultra high performance fiber reinforced cementitious composites. Compos. Struct. 106(Supplement C): 742-753 